\title{
Clinical Experience with Immune Monitoring for Cytomegalovirus in Solid-Organ Transplant Recipients
}

\author{
Oriol Manuel
}

Published online: 29 September 2013

(C) Springer Science+Business Media New York 2013

\begin{abstract}
Novel strategies are needed to further reduce the burden of cytomegalovirus (CMV) disease in solid-organ transplant (SOT) recipients. Measurement of the specific cellmediated immunity against CMV can identify the actual risk for the development of CMV disease in a given patient. Thus, immune monitoring is an attractive strategy for individualizing the management of CMV after transplantation. A growing number of observational studies on immune monitoring for CMV have been published over recent years, although there is a lack of data coming from interventional trials. In high-risk patients, measurement of CMV-specific T-cell responses appropriately stratifies the risk of CMV disease after discontinuation of antiviral prophylaxis. Immune monitoring may also help to identify patients followed by the preemptive approach at low risk for progression to CMV disease. Pretransplant assessment of cell-mediated immunity in seropositive patients may predict the development of posttransplant CMV infection. Overall, these studies indicate that the use of cell-mediated immunity assays has the potential to improve the management of CMV disease in SOT recipients.
\end{abstract}

Keywords Cell-mediated immunity · Quantiferon-CMV . ELISPOT $\cdot$ Prevention

\section{Introduction}

Cytomegalovirus (CMV) is considered the number one viral pathogen after organ transplantation $[1 \bullet \bullet, 2]$. CMV disease has been associated with significant morbidity and even mortality

O. Manuel $(\square)$

Infectious Diseases Service and Transplantation Center, University Hospital (CHUV) and University of Lausanne, MP14-316. CHUV, 1011 Lausanne, Switzerland

e-mail: oriol.manuel@chuv.ch in solid-organ transplant (SOT) recipients [3]. However, over the last decade, major improvements in the prevention and management of CMV disease have been achieved, due to the introduction of universal antiviral strategies after transplantation $[4,5]$. Currently, overall incidence of CMV disease is below $10 \%$ in some transplant programs [6,7], and when occurring, CMV disease is usually managed on an outpatient basis using oral antiviral drugs. Despite these improvements, the prevention of CMV remains challenging. In the subgroup of patients at high risk (the seronegative recipient of an organ from a seropositive donor, [D+/R-]), incidence of CMV disease may be as high as $30 \%-40 \%$ [8]; thus, a better identification of the actual risk for developing CMV would be useful for individualizing the management of CMV. On the contrary, patients at very low risk for CMV may benefit from minimal preventive strategies, thus reducing costs and the toxicity associated with the use of antiviral drugs [9].

Because cell-mediated immunity is known to be the key player in controlling CMV replication after transplantation, measurement of the specific T-cell response against CMV may stratify patients according to the individual risk for developing CMV disease. I review here the recent literature on the clinical application of immune monitoring for CMV for improving the preventive strategies against CMV disease after transplantation.

\section{Cell-Mediated Immunity Assays}

The adaptive immune system, and particularly T-cell immunity, plays an important role in the immunological control of CMV in SOT recipients. The mechanisms involved in the cellular immune response to CMV after transplantation have been recently reviewed elsewhere $[10,11]$. Both CD8+ and CD4+ T-cells participate in the immune response to CMV. CD8+ T-cells are mainly involved early after transplantation 
and are necessary to establish an immune response following primary infection, while CD4+ T-cells seem to be more implicated in establishing a long-term immune control against CMV [11]. Recent studies have also evaluated the antiviral role of other lymphocyte subpopulations, such as Treg, Th17, and $\gamma-\delta$ T-cells $[12,13]$.

Several assays are available for the measurement of CMVspecific cell-mediated immunity. Most of these tests rely on the detection of interferon- $\gamma$ after in vitro stimulation of T-cells with CMV peptides or infected cell lysates. Importantly, over the last few years, some standardized commercial assays have become available, which is an essential requirement for including these assays in the research agenda and, eventually, in the routine clinical practice.

The Quantiferon-CMV assay (Cellestis, Australia) is an ELISA-based assay that detects the release of interferon- $\gamma$ after in vitro stimulation in whole blood by a pool of HLArestricted CMV epitopes [14]. The assay consists of three tubes: a CMV tube coated with the CMV epitopes, a mitogen tube with phytohemagglutinine used as a positive control, and a nil tube used as a negative control [15]. A positive result of the assay requires a detectable release of interferon- $\gamma$ from the CMV tube. Most of the studies have used a cutoff for positivity of $>0.2 \mathrm{IU} / \mathrm{ml}$, although in $\mathrm{D}+/ \mathrm{R}^{-}$patients, a cutoff of $>0.1 \mathrm{IU} / \mathrm{ml}$ increases sensitivity and, therefore, seems to be more appropriate $[15,16]$. An indeterminate result is given when both the CMV tube and the mitogen tube are nonreactive, and this has been related to anergy (usually following the use of T-cell-depleting agents) [17•]. In healthy volunteers, the Quantiferon-CMV correlates well with the CMV serostatus, although in immunocompromised patients, a significant number of seropositive patients may not have a detectable cell-mediated response by the QuantiferonCMV assay [18]. In a study involving hematopoietic stem cell transplant (HSCT) recipients, the Quantiferon-CMV assay appropriately correlated with polyfunctional CMV-specific CD8+ T-cell responses [19]. The Quantiferon-CMV assay is $\mathrm{CE}$ approved.

The ELISPOT assay detects the release of interferon- $\gamma$ by CD4+ and CD8+ T-cells after stimulation of peripheral blood mononuclear cells (PBMCs) by CMV antigens (CMV-specific T-cell epitopes or whole infected cell lysates) [10]. Most studies have used a home-made assay for the evaluation of the T-cell response; thus, comparison of results between studies is difficult [20-22]. Of note, the technique of the ELISPOT is cumbersome, especially as compared with the Quantiferon-CMV assay. A commercial ELISPOT is CE approved (T-Track CMV, Lophius, Germany), but experience in its use in SOT recipients is limited. There is no standard cutoff for positivity of the ELISPOT assay, although it is generally accepted that a cutoff from 5 to 50 spot-forming cells (SFCs) defines a detectable T-cell response [20]. A recent study comparing the Quantiferon-CMV assay and an ELISPOT-CMV assay in kidney transplant recipients found that a cutoff above 150 SFCs/200,000 PBMCs of the ELISPOT was associated with protection from CMV infection [23].

Intracellular cytokine staining (ICS) detects interferon- $\gamma$ and other cytokines by flow cytometry. Whole blood or PBMCs are stimulated with CMV peptides/lysate. Of note, staining of stimulated PBMCs allows not only quantification, but also the characterization of CMV-specific CD4+ and CD8+ T-cells; therefore, a more accurate assessment of the specific cellmediated immunity is obtained using ICS [24-27]. A disadvantage of this assay is the need for a flow cytometer, so that it is difficult to implement outside a research laboratory.

A new commercial assay named Dextramer ${ }^{\circledR}$ CMV Kit (Immudex, Denmark) contains a dextran polymer carrying multiple MHC-CMV peptide complexes. The CMV dextramer recognizes CMV-specific T-cell receptors on the surface of $\mathrm{CD} 8+\mathrm{T}$ cells and can detect and quantify CMV-specific T-cells by flow cytometry. Experience with this assay is limited so far to HSCT recipients.

\section{Current Challenges in the Prevention of CMV Disease in SOT Recipients}

Two main strategies are currently used for the prevention of CMV in SOT recipients - namely, antiviral prophylaxis and preemptive therapy [2]. Prophylaxis relies on the administration of an antiviral drug during the period of highest risk for CMV - that is, 3-6 months posttransplant. The preemptive approach consists in monitoring the CMV viral load and in starting antiviral therapy once viremia is detected, before the development of symptoms. The choice of each strategy is generally determined at the time of transplantation by the estimated risk for developing CMV disease. $\mathrm{D}^{+} / \mathrm{R}-$ patients generally receive antiviral prophylaxis, while seropositive $(\mathrm{R}+)$ recipients can be managed by either the preemptive approach or prophylaxis [28]. In addition, patients who receive T-cell-depleting antibodies as induction therapy or therapy for rejection are considered at high risk and, therefore, more commonly receive antiviral prophylaxis $[1 \bullet \bullet, 2]$.

Late-onset CMV disease refers to the development of CMV disease after the discontinuation of antiviral prophylaxis [29]. While this is quite uncommon in $\mathrm{CMV} \mathrm{R}+$ patients (usually less than $5 \%$ ) [6], late-onset CMV disease incidence may reach up to $30 \%-40 \%$ in high-risk $\mathrm{D}+/ \mathrm{R}-$ patients in some series $[8,30,31]$. There is no consensus in the literature as to whether late-onset CMV disease is associated with impaired transplant outcomes, since it was shown for early-onset CMV disease before the introduction of universal preventive strategies [3]. Some studies found that patients with late-onset CMV disease had a higher incidence of graft loss and even all-causes mortality [32, 33], while some recent prospective cohorts did not confirm these results $[6,34]$. Extending the duration of 
antiviral prophylaxis to 6 or 12 months (depending on the type of organ) further reduces CMV disease incidence, but at some cost $[8,30]$. Monitoring of CMV viral load after discontinuation of antiviral prophylaxis (i.e., a hybrid approach) may identify patients with asymptomatic viremia at risk for subsequently developing CMV disease. However, this is difficult to implement, and it is not currently recommended in the routine clinical practice $[35,36]$.

In patients at intermediate risk for the development of CMV disease, the standard duration of 3 months of antiviral prophylaxis may be associated with some toxicity [9]. Even if followed by the preemptive approach, some patients with asymptomatic viremia may not subsequently develop CMV disease if untreated, since the recipient immune response may spontaneously control CMV viremia [37]. Therefore, identification of patients at very low risk for the development of CMV disease may reduce the administration of antiviral drugs (either prophylactically or preemptively) and, therefore, avoid their overuse.

\section{Clinical Experience with Immune Monitoring in the Prevention of CMV Disease}

Since a detectable specific T-cell response against CMV is correlated with an appropriate immune control of CMV of the recipient [10], the monitoring of cell-mediated immunity may be useful in establishing the real risk for developing CMV disease after transplantation and, therefore, for individualizing preventive strategies accordingly. The clinical experience with the use of immune monitoring for CMV is still limited, although a growing number of articles have been published over recent years. Importantly, the cell-mediated immune assays have been assessed in different clinical scenarios, including SOT recipients both at high-risk and at low risk for developing CMV disease after discontinuation of antiviral prophylaxis and patients managed by preemptive therapy. This growing knowledge is essential to delineating the most cost-effective strategies for integrating immune monitoring in the prevention of CMV disease. Table 1 shows the potential clinical scenarios for the use of cell-mediated immune assays in the prevention of CMV disease.

Predicting Late-Onset CMV Disease After Discontinuation of Antiviral Prophylaxis

Since $\mathrm{D}+/ \mathrm{R}$ - patients are at highest risk for developing lateonset CMV disease, most studies have targeted this population in the assessment of immune monitoring for CMV, although other high-risk patients (lung transplant recipients or patients receiving T-cell-depleting antibodies) have also been included in these studies. In a study by Kumar et al., patients at high risk for the development of CMV disease were monitored with the
Quantiferon-CMV assay for the duration of prophylaxis [16]. Patients with a positive result for the assay at the end of prophylaxis had a lower incidence of late-onset CMV disease $(3.3 \%$ in patients with interferon- $\gamma$ levels $>0.2 \mathrm{IU} / \mathrm{ml}$, as compared with $21.8 \%$ in patients with a negative response, $p=.04)$. In $\mathrm{D}+/ \mathrm{R}-$ patients, incidence of $\mathrm{CMV}$ disease was $10 \%$ in patients with a detectable CD8+ T-cell response, as compared with $40 \%$ in patients with no response. In another study performed in lung transplant recipients, the result of the Quantiferon-CMV assay predicted the incidence of CMV viremia ( $25 \%$ vs. $72 \%$ in patients with a positive, as compared with a negative, result, respectively) [38]. Of note, all 4 patients who eventually developed CMV disease had a previous undetectable cell-mediated immune response. Finally, in a recent study involving an international multicenter cohort of 126 $\mathrm{D}+/ \mathrm{R}-\mathrm{SOT}$ recipients, the Quantiferon-CMV assay was performed at the time of discontinuation of antiviral prophylaxis and two times thereafter [17•]. Patients with a positive assay had a lower incidence (4\%) of CMV disease than did patients with a negative result $(22 \%)$ and an indeterminate result $(58 \%)$ of the assay $(p<.001$; see Fig. 1$)$. The positive predictive value (i.e., protection from CMV disease in patients with a positive assay) was .93 , although because of low sensitivity, the negative predictive value of the assay was only moderate $(.27)$.

Taken together, the data from these studies indicate that $\mathrm{D}+/ \mathrm{R}-$ patients who develop a specific CMV T-cell response during or after discontinuation of antiviral prophylaxis are protected against CMV disease. These patients may benefit from a reduction in the duration of prophylaxis and/or no additional surveillance. A significant number of patients with a negative test will never develop CMV disease, so increasing the sensitivity of cell-mediated immune assays would be desirable in order to better stratify this group of patients. Patients with an indeterminate result represent a highly immunosupressed population at very high risk for developing CMV disease. These patients will likely benefit from a reduction in immunosuppression or from prolonged antiviral prophylaxis.

Monitoring of Preemptive Therapy in Asymptomatic Patients with CMV Viremia

Cell-mediated immunity assays may also guide the use of antiviral therapy in patients followed by the preemptive approach. Because a positive cell-mediated immune response identifies patients at low risk for CMV disease, the decision to start antiviral therapy in patients with asymptomatic CMV DNAemia may be taken according to the result of the immune assay, thus avoiding the excessive use of antiviral drugs in patients at low risk for progression to CMV disease. This approach has been studied in a prospective study involving 37 SOT recipients who were followed by the preemptive 
Table 1 Potential clinical application of immune monitoring in the management of cytomegalovirus (CMV) after organ transplantation

\begin{tabular}{|c|c|c|c|}
\hline Clinical scenario & Aim of immune monitoring & $\begin{array}{l}\text { Result of } \\
\text { the assay }\end{array}$ & Consequence \\
\hline \multicolumn{4}{|l|}{$\mathrm{D}+/ \mathrm{R}-$ and $\mathrm{R}+$ patients $^{1}$} \\
\hline \multirow[t]{2}{*}{ During antiviral prophylaxis } & \multirow[t]{2}{*}{ To determine the duration of prophylaxis } & Positive & - Stop prophylaxis \\
\hline & & Negative & $\begin{array}{l}\text { - Prolong prophylaxis or close monitoring after } \\
\text { discontinuation of prophylaxis }\end{array}$ \\
\hline \multirow[t]{2}{*}{ After antiviral prophylaxis } & \multirow{2}{*}{$\begin{array}{l}\text { To determine the risk for developing CMV } \\
\text { disease }\end{array}$} & Positive & - No further monitoring \\
\hline & & Negative & $\begin{array}{l}\text { - Close monitoring or reduction of } \\
\text { immunosuppression }\end{array}$ \\
\hline \multirow[t]{2}{*}{ During preemptive therapy } & \multirow{2}{*}{$\begin{array}{l}\text { To determine the progression to } \\
\text { symptomatic CMV disease }\end{array}$} & Positive & - Withhold antiviral therapy ${ }^{2}$ \\
\hline & & Negative & - Start antiviral therapy \\
\hline \multirow[t]{2}{*}{ Pretransplant evaluation of $\mathrm{R}+$ patients $^{3}$} & \multirow{2}{*}{$\begin{array}{l}\text { To determine the risk for developing } \\
\text { posttransplant CMV disease }\end{array}$} & Positive & - No prevention needed \\
\hline & & Negative & - Administer prophylaxis/preemptive therapy \\
\hline \multirow[t]{2}{*}{ In patients post-CMV disease } & \multirow{2}{*}{$\begin{array}{l}\text { To determine the risk for relapse after } \\
\text { discontinuation of antiviral therapy }\end{array}$} & Positive & - No secondary prophylaxis needed \\
\hline & & Negative & - Administer secondary prophylaxis \\
\hline \multirow{2}{*}{$\begin{array}{l}\text { In patients receiving anti-rejection therapy } \\
\text { (with T-cell depleting agents) }\end{array}$} & \multirow{2}{*}{$\begin{array}{l}\text { To determine the risk for developing CMV } \\
\text { disease }\end{array}$} & Positive & - No prevention needed \\
\hline & & Negative & - Administer prophylaxis/preemptive therapy \\
\hline
\end{tabular}

All of these indications for immune monitoring need validation in interventional trials. Adapted from Kotton et al. [1••]

${ }^{1}$ Particularly in patients receiving induction therapy with T-cell-depleting antibodies

${ }^{2}$ In D+/R- patients, because of the high risk for progression to CMV disease, even patients with a positive immune assay may require antiviral therapy

${ }^{3}$ In patients not receiving T-cell-depleting antibodies

approach (either early after transplant or after discontinuation of antiviral prophylaxis) [37]. Most patients (24/26, $92 \%)$ who had a positive Quantiferon-CMV assay spontaneously cleared CMV DNAemia without need of antiviral therapy. On the contrary, patients with a negative Quantiferon-CMV at the time of CMV DNAemia received more antiviral therapy $(7 / 11,63 \%)$. Despite the modest sample size, this

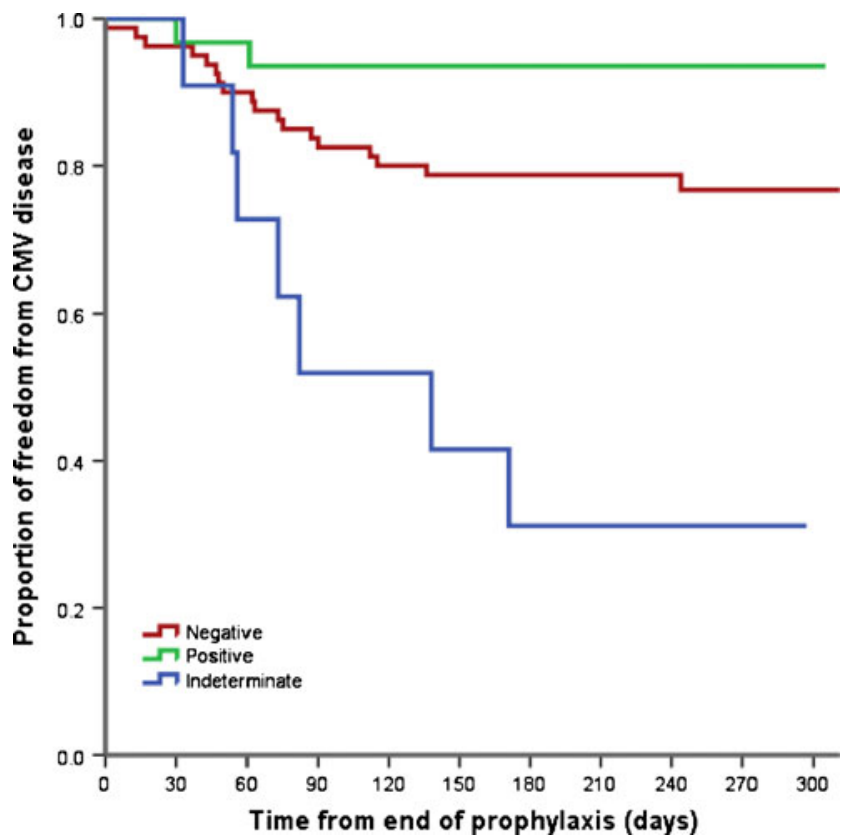

Fig. 1 Kaplan-Meier curves of the incidence of cytomegalovirus (CMV) disease according to the result of the Quantiferon-CMV assay (log-rank test, $p<.001)$. See the text for definitions. Used with permission from Manuel et al. [17•] study suggests that antiviral therapy could be safely withheld in patients with a detectable cell-mediated response to CMV. An interventional trial integrating immune monitoring in the management of patients followed by the preemptive approach is ongoing.

\section{Pretransplant Assessment of Seropositive Patients}

Pretransplant CMV serology remains an essential tool for stratifying the risk of developing CMV disease posttransplant $[1 \bullet \bullet]$. The role of assessing pretransplant cell-mediated immunity status in estimating the risk for CMV replication posttransplant has been recently analyzed [18, 22]. In a study of Cantisán et al., the Quantiferon-CMV assay was performed pretransplant in 55 lung and kidney transplant recipients [18]. In $\mathrm{R}+$ patients, the Quantiferon assay was reactive in only two thirds of the patients. Interestingly, $\mathrm{R}+$ patients with a nonreactive Quantiferon-CMV assay had a significant higher risk for developing posttransplant CMV DNAemia than did patients with a reactive Quantiferon-CMV (50\% vs. $13 \%$, respectively). In addition, all 5 patients who developed CMV disease had a nondetectable T-cell response. In a study by Bestard et al., an ELISPOT assay was used at baseline and 6 months after transplantation in 137 kidney transplant recipients [22]. Pretransplant anti-IE-1-specific T-cell responses were significantly lower in patients with posttransplant CMV infection, and they appropriately predicted the risk for CMV replication in both $\mathrm{R}+$ and $\mathrm{D}+/ \mathrm{R}-$ patients. Overall, the measurement of pretransplant cell-mediated immunity appears to be an additional tool for better defining the risk for posttransplant CMV infection, irrespectively of the CMV serostatus. 


\section{Future Research}

The main conclusion that we can draw from all the recent experience with the use of immune monitoring for CMV is that it has an excellent positive predictive value for predicting protection from CMV disease but that an enhancement of the sensitivity of the assay would be necessary to improve the performance of cell-mediated immunity assays in routine clinical practice. Additional studies are needed to assess the performance of immune monitoring for CMV in specific clinical situations, such as the need for antiviral prophylaxis in patients receiving antirejection therapy, or to predict the relapse of CMV disease after discontinuation of antiviral therapy (Table 1). In addition, the relationship between a detectable cell-mediated immunity against CMV and other transplant outcomes, such as graft function, has not been evaluated yet. More important, so far, all the data generated on the use of immune monitoring have been extracted from observational studies. We need interventional randomized controlled trials to know the added value of immune monitoring for CMV in the management of CMV disease. The availability of new commercial assays, standardized and easy to perform in any transplant center, should facilitate the implementation of such interventional studies. Given the rapidly growing experience with the use of cell-mediated immunity assays, it can be expected that, similarly to their use in the diagnosis of latent tuberculosis, immune monitoring may become part of the standard of care for the prevention of CMV disease after solid-organ transplantation.

\begin{abstract}
Acknowledgments The author thanks Prof. Pascal Meylan, from the Institute of Microbiology, University Hospital (CHUV) and University of Lausanne, Switzerland, for the revision of the manuscript and helpful discussions.
\end{abstract}

\section{Compliance with Ethics Guidelines}

Conflict of Interest Oriol Manuel declares no conflict of interest.

Human and Animal Rights and Informed Consent This article does not contain any studies with human or animal subjects performed by any of the authors.

\section{References}

Papers of particular interest, published recently, have been highlighted as:

- Of importance

-• Of major importance

1. $\bullet$ Kotton CN, Kumar D, Caliendo AM, Asberg A, Chou S, DanzigerIsakov L, et al. Updated International Consensus Guidelines on the Management of Cytomegalovirus in Solid-Organ Transplantation. Transplantation. 2013;96:333-60. Updated and comprehensive guidelines on the management of CMV after transplant with a "state-of-the-art" chapter on immune monitoring.

2. Razonable RR, Humar A. Practice ASTIDCo. Cytomegalovirus in solid organ transplantation. Am J Transplant. 2013;13 Suppl 4:93106.

3. Peterson PK, Balfour Jr HH, Marker SC, Fryd DS, Howard RJ, Simmons RL. Cytomegalovirus disease in renal allograft recipients: a prospective study of the clinical features, risk factors and impact on renal transplantation. Medicine. 1980;59(4):283300.

4. Hodson EM, Jones CA, Webster AC, Strippoli GF, Barclay PG, Kable K, et al. Antiviral medications to prevent cytomegalovirus disease and early death in recipients of solid-organ transplants: a systematic review of randomised controlled trials. Lancet. 2005;365(9477):2105-15.

5. Kalil AC, Levitsky J, Lyden E, Stoner J, Freifeld AG. Meta-analysis: the efficacy of strategies to prevent organ disease by cytomegalovirus in solid organ transplant recipients. Ann Intern Med. 2005;143(12): 870-80.

6. Manuel O, Kralidis G, Mueller NJ, HIrsch HH, Garzoni C, van Deden $\mathrm{C}$, et al. Impact of antiviral preventive strategies on the incidence and outcomes of cytomegalovirus disease in solid-organ transplant recipients. Am J Transplant. 2013;13:2402-10.

7. San Juan R, Aguado JM, Lumbreras C, Fortun J, Munoz P, Gavalda J, et al. Impact of current transplantation management on the development of cytomegalovirus disease after renal transplantation. Clin Infect Dis. 2008;47(7):875-82.

8. Humar A, Lebranchu Y, Vincenti F, Blumberg EA, Punch JD, Limaye AP, et al. The efficacy and safety of 200 days valganciclovir cytomegalovirus prophylaxis in high-risk kidney transplant recipients. Am J Transplant. 2010;10(5):1228-37.

9. Manuel O, Venetz JP, Fellay J, Wasserfallen JB, Sturzenegger N, Fontana M, et al. Efficacy and safety of universal valganciclovir prophylaxis combined with a tacrolimus/mycophenolate-based regimen in kidney transplantation. Swiss Med Weekly. 2007;137(47-48):669-76.

10. Crough T, Khanna R. Immunobiology of human cytomegalovirus: from bench to bedside. Clin Microbiol Rev. 2009;22(1):76-98. Table of Contents.

11. Egli A, Humar A, Kumar D. State-of-the-art monitoring of cytomegalovirus-specific cell-mediated immunity after organ transplant: a primer for the clinician. Clin Infect Dis. 2012;55(12):167889.

12. Couzi L, Lafarge X, Pitard V, Neau-Cransac M, Dromer C, Billes MA, et al. Gamma-delta $\mathrm{T}$ cell expansion is closely associated with cytomegalovirus infection in all solid organ transplant recipients. Transplant Int. 2011;24(5):e40-2.

13. Egli A, Silva Jr M, O'Shea D, Wilson LE, Baluch A, Lisboa LF, et al. An analysis of regulatory T-cell and Th-17 cell dynamics during cytomegalovirus replication in solid organ transplant recipients. PLoS One. 2012;7(11):e43937.

14. Giulieri S, Manuel O. QuantiFERON(R)-CMV assay for the assessment of cytomegalovirus cell-mediated immunity. Expert Rev Mol Diagn. 2011;11(1):17-25.

15. Walker S, Fazou C, Crough T, Holdsworth R, Kiely P, Veale M, et al. Ex vivo monitoring of human cytomegalovirus-specific CD8+ T-cell responses using QuantiFERON-CMV. Transplant Infect Dis. 2007;9(2):165-70.

16. Kumar D, Chernenko S, Moussa G, Cobos I, Manuel O, Preiksaitis J, et al. Cell-mediated immunity to predict cytomegalovirus disease in high-risk solid organ transplant recipients. Am J Transplant. 2009;9(5):1214-22.

17. - Manuel O, Husain S, Kumar D, Zayas C, Mawhorter S, Levi $\mathrm{ME}$, et al. Assessment of cytomegalovirus-specific cell-mediated immunity for the prediction of cytomegalovirus disease in highrisk solid-organ transplant recipients: a multicenter cohort study. 
Clin Infect Dis. 2013;56(6):817-24. This large international study showed that patients with a detectable cell-mediated immune response to $C M V$ at the discontinuation of prophylaxis were protected against the subsequent development of $C M V$ disease.

18. Cantisan S, Lara R, Montejo M, Redel J, Rodriguez-Benot A, Gutierrez-Aroca $\mathrm{J}$, et al. Pretransplant interferon-gamma secretion by $\mathrm{CMV}$-specific CD8+ T cells informs the risk of CMV replication after transplantation. Am J Transplant. 2013;13(3): 738-45.

19. Clari MA, Munoz-Cobo B, Solano C, Benet I, Costa E, Remigia MJ, et al. Performance of the QuantiFERON-cytomegalovirus (CMV) assay for detection and estimation of the magnitude and functionality of the CMV-specific gamma interferon-producing CD8(+) T-cell response in allogeneic stem cell transplant recipients. Clin Vaccine Immunol. 2012;19(5):791-6.

20. Abate D, Fiscon M, Saldan A, Cofano S, Mengoli C, Sgarabotto D, et al. Human cytomegalovirus-specific T-cell immune reconstitution in preemptively treated heart transplant recipients identifies subjects at critical risk for infection. J Clin Microbiol. 2012;50(6): 1974-80.

21. Abate D, Saldan A, Fiscon M, Cofano S, Paciolla A, Furian L, et al. Evaluation of cytomegalovirus (CMV)-specific T cell immune reconstitution revealed that baseline antiviral immunity, prophylaxis, or preemptive therapy but not antithymocyte globulin treatment contribute to CMV-specific $\mathrm{T}$ cell reconstitution in kidney transplant recipients. J Infect Dis. 2010;202(4):585-94.

22. Bestard O, Lucia M, Crespo E, Van Liempt B, Palacio D, Melilli E, et al. Pretransplant immediately early-1-specific $\mathrm{T}$ cell responses provide protection for CMV infection after kidney transplantation. Am J Transplant. 2013;13(7):1793-805.

23. Abate D, Saldan A, Mengoli C, Fiscon M, Silvestre C, Fallico L, et al. Comparison of cytomegalovirus (CMV) enzyme-linked immunosorbent spot and CMV quantiferon gamma interferon-releasing assays in assessing risk of CMV infection in kidney transplant recipients. J Clin Microbiol. 2013;51:2501-7.

24. Egli A, Binet I, Binggeli S, Jager C, Dumoulin A, Schaub S, et al. Cytomegalovirus-specific T-cell responses and viral replication in kidney transplant recipients. J Transl Med. 2008;6:29.

25. Gerna G, Lilleri D, Chiesa A, Zelini P, Furione M, Comolli G, et al. Virologic and immunologic monitoring of cytomegalovirus to guide preemptive therapy in solid-organ transplantation. Am J Transplant. 2011;11(11):2463-71.

26. Mattes FM, Vargas A, Kopycinski J, Hainsworth EG, Sweny P, Nebbia G, et al. Functional impairment of cytomegalovirus specific CD8 T cells predicts high-level replication after renal transplantation. Am J Transplant. 2008;8(5):990-9.
27. Nebbia G, Mattes FM, Smith C, Hainsworth E, Kopycinski J, Burroughs A, et al. Polyfunctional cytomegalovirus-specific CD4+ and pp $65 \mathrm{CD} 8+\mathrm{T}$ cells protect against high-level replication after liver transplantation. Am J Transplant. 2008;8(12):2590-9.

28. Le Page AK, Jager MM, Kotton CN, Simoons-Smit A, Rawlinson WD. International survey of cytomegalovirus management in solid organ transplantation after the publication of consensus guidelines. Transplantation. 2013;95(12):1455-60.

29. Meylan PR, Manuel O. Late-onset cytomegalovirus disease in patients with solid organ transplant. Curr Opin Infect Dis. 2007;20(4): 412-8.

30. Palmer SM, Limaye AP, Banks M, Gallup D, Chapman J, Lawrence EC, et al. Extended valganciclovir prophylaxis to prevent cytomegalovirus after lung transplantation: a randomized, controlled trial. Ann Intern Med. 2010;152(12):761-9.

31. Paya C, Humar A, Dominguez E, Washburn K, Blumberg E, Alexander B, et al. Efficacy and safety of valganciclovir vs. oral ganciclovir for prevention of cytomegalovirus disease in solid organ transplant recipients. Am J Transplant. 2004;4(4):611-20.

32. Arthurs SK, Eid AJ, Pedersen RA, Kremers WK, Cosio FG, Patel R, et al. Delayed-onset primary cytomegalovirus disease and the risk of allograft failure and mortality after kidney transplantation. Clin Infect Dis. 2008:46(6):840-6.

33. Limaye AP, Bakthavatsalam R, Kim HW, Randolph SE, Halldorson JB, Healey PJ, et al. Impact of cytomegalovirus in organ transplant recipients in the era of antiviral prophylaxis. Transplantation. 2006;81(12):1645-52.

34. San-Juan R, De Dios B, Garcia-Reyne A, Fernandez-Ruiz M, Lumbreras C, Lopez-Medrano F, et al. Limited impact of cytomegalovirus infection in the long-term outcome of renal and liver transplant. J Clin Virol. 2013;56(4):316-22.

35. Boillat Blanco N, Pascual M, Venetz JP, Nseir G, Meylan PR, Manuel O. Impact of a preemptive strategy after 3 months of valganciclovir cytomegalovirus prophylaxis in kidney transplant recipients. Transplantation. 2011;91(2):251-5.

36. Lisboa LF, Preiksaitis JK, Humar A, Kumar D. Clinical utility of molecular surveillance for cytomegalovirus after antiviral prophylaxis in high-risk solid organ transplant recipients. Transplantation. 2011;92(9):1063-8.

37. Lisboa LF, Kumar D, Wilson LE, Humar A. Clinical utility of cytomegalovirus cell-mediated immunity in transplant recipients with cytomegalovirus viremia. Transplantation. 2012;93(2):195-200.

38. Weseslindtner L, Kerschner H, Steinacher D, Nachbagauer R, Kundi M, Jaksch P, et al. Prospective analysis of human cytomegalovirus DNAemia and specific CD8+ T Cell responses in lung transplant recipients. Am J Transplant. 2012;12(8):2172-80. 